\title{
FOTO CINEMA -

\section{El cielo gira (2004): el contramonumento de Mercedes Álvarez a la idea de progreso}

\section{The Sky Turns (2004): Mercedes Álvarez's counter-monument to the idea of progress}

\author{
Georgina Oller Bosch \\ University of Califonia, Davis, USA \\ gollerbosch@ucdavis.edu
}

\section{Resumen:}

En 2020 se cumplen 16 años del estreno de El cielo gira, ópera prima de Mercedes Álvarez. La cineasta española, hija de Aldealseñor, hizo de esta localidad de Soria (Castilla y León) el escenario de su multipremiado documental en 2004. En este tiempo, conforme con la sinopsis del film incluida en el DVD comercial, en la aldea vivían sólo 14 hombres y mujeres y ningún menor de edad. Álvarez fue y parece ser la última persona nacida en Aldealseñor y el trabajo que firma, proyecta el viaje de vuelta a su pueblo de origen para reencontrarse con los vecinos del lugar mientras este vive una transformación modernizadora impuesta, oficialmente, por la necesidad de frenar la despoblación. Extraoficialmente, El cielo gira, utilizando la terminología de James E. Young, puede leerse como el contramonumento que Álvarez erige a la idea de progreso.

\begin{abstract}
:
The year 2020 marks the 16th anniversary of the premiere of The Sky Turns, Mercedes Álvarez's debut feature. Originally from Aldealseñor, Álvarez turns the spotlight on this tiny village in Soria (Castilla y León) as the real protagonist of her multi-awarded documentary. According to the synopsis of the film included in the commercial DVD, at that time only 14 men and women still lived there, none of them under age. Alvarez was, and still is, the last person born in Aldealseñor: The Sky Turns follows her return to her homeplace where she meets the locals at a time when the village is undergoing a process of modernisation devised, officially, with the aim of arresting its depopulation. Unofficially, though, The Sky Turns may be read as the counter-monument (to use the term coined by James E. Young) erected against an idea notion of progress.
\end{abstract}

Palabras clave: El cielo gira; documental; contramonumento; memoria; progreso.

Keywords: The Sky Turns; documentary; counter-monument; memory; progress. 


\section{Introducción}

En 2012 Efrén Cuevas afirmaba que El cielo gira (Mercedes Álvarez, 2004) era ejemplo aventajado de un nuevo tipo de documentalismo. Concretamente, Cuevas señalaba que el documental de Álvarez se podía considerar la mejor película autobiográfica hecha en España hasta esa fecha (Cuevas, 2012, p. 80). Sin discutir ahora la consideración de Cuevas, el presente artículo quiere poner atención en otro atributo vanguardista del largometraje hasta el momento no apercibido. El cielo gira, además de ser un film autobiográfico de inevitable referencia, puede catalogarse como uno de los primeros documentales contramonumentales del cine español. El trabajo es una obra contramonumental porque esta no es un monumento al discurso dominante que propugna la pertinencia de implementar proyectos de inversión económica para modernizar aldeas y pueblos y para, así, poder prevenir y frenar su desaparición. Tampoco es, este, un largometraje producido con el fin de monumentalizar el discurso contrario, un contradiscurso $^{1}$ alternativo al oficial. Por las razones esgrimidas sobre el funcionamiento comunicativo del film y por otras, basadas en las características conceptuales y formales del documental examinadas a lo largo del ensayo, El cielo gira, utilizando la terminología de James E. Young, podría definirse como el contramonumento cinematográfico que Álvarez erige a la idea de progreso.

Con el propósito de justificar la tesis acabada de plantear, siempre a través del análisis de planos, escenas o secuencias del largometraje, en el primer apartado de este artículo constato que El cielo gira se ajusta al concepto de contramonumento al estudiar qué realidad (re)construye el trabajo de Álvarez. En el segundo apartado, argumento sobre la forma de contramonumento que toma el documental al exponer cómo y por qué la realizadora ofrece un retrato de Aldealseñor y de sus habitantes desde la subjetividad. Finalmente, en el tercer y último apartado del texto, concluyo que El cielo gira funciona como un contramonumento después de examinar la relación comunicativa que la realizadora propone a la audiencia. La

${ }^{1}$ Utilizo el término 'contradiscurso' tal y como lo define Richard Terdiman (2018, pp. 6566). 
documentalista no impone al público ninguna verdad absoluta sobre la necesidad o no de inversiones en la aldea porque Álvarez cree en la capacidad de los espectadores para llegar por sí mismos a algún tipo de conclusión a partir de las imágenes filmadas y editadas por ella. Tal como concibe y da forma a su documental, la directora viabiliza que los integrantes del público puedan dejar de ser meros receptores pasivos de mensajes producidos por otros.

\section{El documental: una construcción cinematográfica de la realidad $^{2}$}

La sinopsis que acompaña el DVD comercial de El cielo gira presenta el documental como una película sobre "la última generación [de habitantes de Aldealseñor] después de mil años de historia ininterrumpida”. El resumen del film de Álvarez, que sentencia al grupo de vecinos a extinguirse dentro de poco "sin más testigos", no incluye frase alguna que haga referencia a la transformación modernizadora que experimenta la aldea (Álvarez, 2004). El metraje de El cielo gira, por el contrario, sí incorpora imágenes que van más allá de retratar un año de vida de los aldeanos. El documental sí contiene escenas y secuencias que captan la modernización del lugar impuesta, oficialmente, por la urgencia de frenar la despoblación. Además, la película, también desmintiendo la sinopsis, consigue hacer testigos a 36.885 espectadores $^{3}$ de la evolución socioeconómica de Aldealseñor desde su fundación hasta el presente. Es la realidad (re)construida por medio del film, la que sirve de argumento para justificar en las siguientes páginas que, en cuanto a su concepción, El cielo gira no es un monumento funerario a una generación sino un contramonumento a la idea de progreso.

\footnotetext{
2 El título del apartado reformula el elegido por Bill Nichols, El documental: una ficción (en nada) semejante a cualquier otra, para dar nombre a la segunda parte de su libro $L a$ representación de la realidad (Nichols, 1997, p. 149). Aunque convencionalmente se haya asociado 'ficción' a palabras como 'fantasía' o 'imaginación', este término proviene, según Jacques Rancière, del verbo 'fingere' cuya primera acepción no es "fingir" sino "forjar", que es sinónimo de construir. Según asegura Rancière, lo que distingue una película documental de una no documental no es la forma que toma, es la consideración y el tratamiento de lo real. En el documental, lo real no es un efecto a conseguir, es un dato a comprender (Rancière, 2001, p. 182).

3 Dato extraído del Catálogo de cine español, web del Ministerio de Cultura y Deporte. Recuperado de https://sede.mcu.gob.es/CatalogoICAA/Peliculas/Detalle?Pelicula=45002.
} 
Álvarez tenía tres años el día que sus padres, sus hermanos y ella se marcharon de Aldealseñor4. En El cielo gira, la realizadora se refiere a la salida de su familia de la aldea en estos términos: "Aquella mañana de niebla, los vecinos salieron a despedir el coche que se alejaba por la carretera. El coche con los acarreos que nos llevaba en busca de mejor fortuna" (oo:15:47-00:15:58). La voz en off de la directora en primera persona, sobre un plano-escena del pueblo nieblado5 sin gente en el presente, no revela más sobre el progreso familiar alcanzado. Se da por sentado el progreso vital y socioeconómico de Álvarez porque vuelve a Aldealseñor convertida en cineasta, pero lo único manifiesto en el documental es que ella no invierte ni una palabra, ni una sola imagen para referirse a él. Sin embargo, sí dedica toda una película a retratar el avance del tiempo en la aldea que abandonó de niña. Para ser más precisa en el análisis, la voz de la realizadora, de cuerpo siempre ausente en escena, se focaliza en la narración de un año de vida $-y$ no de muerte- en Aldealseñor. Son las imágenes y los protagonistas del largometraje los que van a aludir, sin tampoco pronunciar el vocablo, las dimensiones políticas, sociales y económicas de la idea progreso.

La definición de progreso como "acción de ir hacia adelante"6, tanto en lo personal como en lo colectivo, puede ser un lugar común. Así lo prueba un artículo de 1979 titulado La idea del progreso y firmado por Robert Nisbet, uno de los grandes sociólogos del siglo XX. En él, Nisbet, inspirándose en un trabajo homónimo de 1920 del historiador y filólogo, J.B. Bury, especifica que "la esencia de la idea de progreso imperante en el mundo occidental puede enunciarse de manera sencilla: la humanidad ha avanzado en el pasado, avanza actualmente y puede esperarse que continúe avanzando en el futuro. Pero cuando preguntamos qué significa "avanzar" las cosas se tornan necesariamente más complejas" (p. 7). La controversia nace cuando tenemos que acordar cómo se avanza colectivamente no solo en el tiempo sino también en lo político, en lo social y en lo económico. El cielo gira, un

\footnotetext{
4 Pamplona, capital de Navarra, es la ciudad de destinación de la familia de Mercedes Álvarez.

5 Término no aceptado por el Diccionario de la Real Academia de la legua española. El adjetivo se elige para describir que la niebla esconde parte de la imagen del pueblo.

${ }^{6}$ Definición extraída del Diccionario de la Real Academia de la legua española. Recuperado de https://dle.rae.es/progreso?m=form.
} 
documental filmado en Soria, una de las regiones más despobladas de Europa7, no aporta respuestas a esta pregunta, a diferencia de un libro que se publicó en el mismo año de su estreno.

The European Dream (Jeremy Rifkin, 2004) sí explicita cuál es el ideal de progreso para Europa y, por consiguiente, también para Aldealseñor: existencia de equilibrio entre los derechos del individuo y las responsabilidades sociales que alberga; primacía de la diversidad sobre la uniformidad cultural, de la calidad de vida sobre la acumulación de la riqueza, y del desarrollo sostenible sobre el crecimiento material ilimitado; prevalencia de los derechos humanos sobre los derechos de propiedad y, además, fomento de la cooperación sobre el ejercicio unilateral del poder (p. 3). En contraste con el libro de Rifkin, Álvarez no ingenia un trabajo también expositivo, aquel que hablando de cine documental Bill Nichols denominaría clásico (Nichols, 1997, p. 53) ${ }^{8}$. El cielo gira no toma forma en torno a la solución del problema o enigma planteado (p. 72) -cómo se progresa en lo político, en lo social y en lo económico- ni hace hincapié en la impresión de objetividad y de juicio bien establecido (p. 68). La cineasta no se inclina a construir un film que, por ejemplo, pudiera utilizar el ejemplo de Aldealseñor para monumentalizar un mensaje sobre qué es y que no es, objetivamente, el ideal de progreso, tomando partido en favor o en contra de posicionamientos como el de Rifkin. Le atrae más producir un trabajo no convencional de tipo contramonumental sobre una población que conoce personalmente desde niña y que en los siglos XX y XXI es escenario de las consecuencias de la aplicación práctica de la idea de progreso. Por este motivo, y por otros en los que se profundiza en el próximo apartado, la realizadora se asoma al mundo de la aldea desde el yo9.

\footnotetext{
7 Dato extraído del web del Parlamento Europeo. Recuperado de https://www.europarl.europa.eu/spain/resource/static/files/PDF/despoblacion_y_cambios demogr-ficos.pdf.

8 Las modalidades de representación de Bill Nichols es la clasificación más influyente en la teoría documental contemporánea (Bruzzi, 2006, p. 3), la más estudiada y a la vez criticada. 9 Stella Bruzzi, que identifica el documental tradicional con aquel que se esfuerza por representar la realidad de la manera más fiel posible basándose en la suposición de que el proceso de producción del film debe disfrazarse, critica la marginación relativa de la tradición documental más reflexiva y performativa (Bruzzi, 2006, p. 186).
} 
Álvarez nunca se ha autoidentificado como cineasta contramonumentalista. No obstante, su documental se sostiene en los pilares del contramonumentalismo descritos a continuación. Conceptualmente, los contramonumentos, al igual que los monumentos ${ }^{10}$, se idean para rememorar sucesos históricos. En cambio, los contramonumentos, a diferencia de los monumentos, no afirman ni desmienten ninguna memoria de lo ocurrido, ni oficial ni alternativa. Los ideadores de contramonumentos no construyen monumentos promotores de narrativas absolutas porque piensan que estos tienden a oficializar una memoria selectiva, que recuerda unos hechos mientras olvida otros. Asimismo, los diseñadores de contramonumentos opinan que los monumentos tienen propensión a desplazar el pasado que deberían hacer contemplar porque, precisamente, sustituyen el trabajo de recordar del que debería ser responsable la sociedad. Los productores de contramonumentos, en contra de los de monumentos, estiman que solo un proceso memorial permanentemente inconcluso es capaz de garantizar que la memoria, de cualquier grupo y sobre cualquier tema, se mantenga viva (Young, 2000, pp. 92-96).

Visto el largometraje, es obvio que la directora, toma parte -que no partido- en la (re)construcción cinematográfica de los hechos ocurridos en Aldealseñor. Citando a Carl R. Plantinga en Rhetoric and Representation in Nonfiction Film (1997), Álvarez construye un texto audiovisual que presenta una determinada información de la aldea y que incluye una "voz" que expresa dicha información desde cierta perspectiva (p. 100). A mi parecer, su perspectiva está en disidencia con el discurso del oficialismo - sobre los beneficios vitales del progreso- $y$, también, aunque de entrada pueda no parecerlo, con el discurso de la oposición al oficialismo - sobre los perjuicios mortales del mismo-, que defiende que todo avance, aunque pueda parecer contradictorio, puede dar origen a nuevos problemas y a pérdidas ${ }^{11}$. Las imágenes de las huellas de dinosaurios, las referentes a antiguos pobladores como celtíberos, numantinos, romanos y árabes; y las de la desaparición de la

${ }^{10}$ Aloïs Riegl puntualiza que el monumento es "una obra [artística o escrita] realizada por la mano humana, creada con el fin específico de mantener hazañas o destinos individuales [. . . ] siempre vivos y presentes en la conciencia de las generaciones venideras" (Riegl, 1987, p. 23).

${ }^{11}$ Para más información, véase Robert Nisbet (1979). 
silla del tío Eliseo ${ }^{12}$, podrían ser usadas para argüir que El cielo gira trata de un progreso que conduce, de una manera u otra, la muerte. Por ello, no es de extrañar que Sergio Cobo Durán y Samuel Neftalí Fernández Pichel lleguen a concluir que el film fue concebido como "monumento funerario" a la última generación de Aldealseñor (2016, p. 30), en línea con la sinopsis del largometraje.

En paralelo a la tesis anterior, otra lectura del documental focalizada en las secuencias sobre la modernización de la aldea, podría dar origen a una conclusión parecida. Las escenas de la instalación de aerogeneradores de viento a las afueras del pueblo y las relacionadas con el acondicionamiento de la torre-palacio ${ }^{13}$ para poner en marcha un hotel podrían impulsar a leer el film como un monumento fúnebre del ruralismo auténtico víctima de un intervencionismo modernizador demoledor. Sin embargo, con base en las mismas imágenes de transformación, se podría defender perfectamente la conclusión contraria, la de la concepción de El cielo gira como monumento a la vida, en favor de la obligatoriedad de llevar a cabo inversiones para impedir el desvanecimiento del medio rural. Más allá de las posibles interpretaciones monumentales del film, un dato prueba la contramonumentalidad de la película: en ningún punto del metraje, la voz en off de Álvarez se detiene para afirmar o desmentir ninguna de las muchas y diversas lecturas y memorias construibles sobre el progreso de la aldea. Al no imponer una lectura única sobre lo sucedido no trata a los espectadores como consumidores de cine ni tampoco como activistas de la memoria sino como posibles y legítimos co-constructores de discursos.

La directora parece no querer difundir por medio de su voz ninguna memoria selectiva que recuerde unos hechos mientras olvida otros. Nuevo indicio de ello es otro pasaje clave del largometraje al inicio de la película. El film comienza con un plano fijo que muestra un cuadro de Pello Azketa en el que

12 El tío Eliseo, comenta la realizadora, solía sentarse en una silla amarilla colocada ante la puerta de la majada (lugar donde se guarda el ganado) a fumar cada tarde antes de caer seriamente enfermo (oo:22:45-00:23:35). La puerta de la majada, sin la silla y con el sonido de las campanas, es metáfora de su fallecimiento (00:35:09-00:36:22).

${ }^{13}$ La construcción, que dio origen a Aldealseñor, forma parte del llamado sistema integral de fortificaciones islámicas del Duero erigido por el Califato de Córdoba ante las incursiones de los condes castellanos en época de la Reconquista (BOCL 158 (2013): 56189). 
unos niños conducen la mirada del espectador hacia las aguas de un pantano. De acuerdo con la voz de Álvarez, los chicos observan "algo [que] ha desaparecido o [que] está a punto de aparecer" (oo:00:45-00:00:52). Esta escena puede considerarse un pilar básico para explicar la concepción de $E l$ cielo gira como contramonumento. No solo porque se encuentra localizada dentro de los primeros segundos del documental sino porque a través de esta pintura de Azketa, la realizadora evita tener que desarrollar y aportar una argumentación explícita acerca del presente y del porvenir histórico, político, social y económico del pueblo. Ella aparenta no querer oficializar una memoria petrificada que desplace el pasado que debería hacer contemplar y que sustituya el trabajo de recordar del que, si acaso, debería ser responsable la sociedad soriana, la española y la europea.

Con el fin de añadir un último argumento en favor del acierto de calificar $\mathrm{El}$ cielo gira de contramonumento, examino otro pasaje del metraje susceptible de ser considerado fundamental, este porque da paso al desenlace de la película. Es aquel en el que tres aldeanos conversan, sentados en la plaza del pueblo, sobre la reforma en curso de la torre-palacio, tertulia que ha merecido poca atención por parte de la crítica, a excepción de Antonio LQuiñones y de Isabel M. Estrada. En esta secuencia, el documental visibiliza otras tres dimensiones del concepto progreso, más allá de la temporal: la social, la económica y la política. En ella, la voz de Álvarez no se escucha. Los protagonistas son únicamente los vecinos y las memorias, más o menos fiables, de cada uno de ellos sobre los detalles de la reconversión de la torrepalacio en un hotel-parador. El diálogo que mantienen se produce delante de la cámara como se produjo en el pasado y como probablemente se producirá con matices en el futuro próximo mientras vivan ellos y sus descendientes. $\mathrm{Al}$ incluir este pasaje, es defendible que la cineasta sea una autora de documentales que estima que solo un proceso memorial permanentemente inconcluso es capaz de garantizar que la memoria, de cualquier grupo y sobre cualquier tema, se mantenga viva.

Los dos hombres y la mujer que intervienen en la charla bromean sobre el hecho de no saber con exactitud qué tipo de hotel se planea abrir, ni para cuándo. Tampoco tienen noticia alguna sobre, por ejemplo, cuántos clientes 
podrá albergar el parador o sobre cuántos trabajadores requerirá. Tres cosas sí saben: 1) la torre-palacio no será una residencia pública para personas mayores; 2) ellos no podrán conseguir un trabajo en el negocio hotelero; y 3) ninguno va a disponer del dinero necesario para poder alojarse en el hotelparador. En menos de tres minutos (01:00:32-01:03:00), la audiencia de $E l$ cielo gira puede interrogarse sobre las razones de la falta de "capacidad de decisión/acción" de los aldeanos; sobre un progreso que parece ser "ajeno a las problemáticas, necesidades y esperanzas de los habitantes" del lugar; y en definitiva, sobre la aparente "opacidad e incontestabilidad con qué funciona el capital” (L-Quiñones, 2007, p. 375). Los espectadores pueden reflexionar libremente acerca del progreso de Aldealseñor (Estrada, 2013, p. 126), sin haber sido instruidos o convencidos por Álvarez sobre nada.

\section{La subjetividad como punto de vista ${ }^{14}$ explícito}

Leonor Arfuch en La vida narrada: memoria, subjetividad y política (2018) precisa que hacia finales de los años 80 se produce una crisis de confianza en la verdad de los grandes relatos de la modernidad, que Jean-François Lyotard resume en cuatro: iluminismo, marxismo, tecnocientifismo capitalista y cristianismo ${ }^{15}$. Arfuch señala que es en el contexto del declive de las grandes narrativas occidentales sobre la tendencia histórica de la humanidad a progresar, cuando ella empieza a darse cuenta de dos hechos: el retorno a la valorización de lo individual/privado/subjetivo/afectivo -ámbitos nacidos en el siglo XVIII con el afianzamiento del capitalismo y con el orden burgués- y la emergencia ineludible de las narrativas del yo en los medios de comunicación, en las artes e incluso en algunas ciencias, como las sociales. Entre estas narrativas del yo, la académica alude específicamente a las producidas en el cine "donde el «documental subjetivo» y la autoficción” dejan, según ella, "una notoria impronta" (Arfuch, 2018, 18). Arfuch -que describe el despliegue del interés generalizado por el sujeto como fuente de

14 Punto de vista: "Cada uno de los modos de considerar un asunto u otra cosa" (Diccionario de la Real Academia de la lengua española, 2019). Recuperado de https://dle.rae.es/punto\#C6I9L3w.

15 Para más detalles, consúltese el capítulo Apostilla de los relatos (pp. 29-32) del libro La posmodernidad (explicada a los niños) escrito por Jean-François Lyotard. 
información y de conocimiento a través del término 'giro subjetivo-, es una fuente valiosa para explicar el porqué de la subjetividad explícita de la realizadora en El cielo gira. Lo son, no menos, Alisa Lebow y Pablo Piedras.

Lebow y Piedras comparten la idea de que al terminar los 80, se inicia una época en la que tiene lugar una revalorización de la subjetividad como herramienta para el conocimiento del mundo histórico, aunque ambos aportan matices a las manifestaciones de Arfuch. En The Cinema of Me. The Self and Subjectivity in First Person Documentary (2012), Lebow pone de relieve que la subjetividad no es de ninguna manera algo nuevo en el documental, a pesar de que la objetividad haya sido el rasgo aceptado tradicionalmente como patrón formal de esta tipología de films. Asimismo, añade que en el último cuarto de siglo, especialmente pero no exclusivamente en Occidente, la primera persona se ha vuelto cada vez más común en el cine y que esta se ha utilizado, entre otros propósitos, para romper con la ilusión de objetividad absoluta en los largometrajes documentales (Lebow, 2012, p. 5). Lebow no habla de 'documental subjetivo' (Varda, 2014, p. 150), de 'documental autobiográfico' (Cuevas, 2012, p. 80 y Renov, 2004, p. 104) o de 'documental autoficcional' (De La Torre, 2015, p. 567). Ella utiliza la expresión 'documental en primera persona' porque permite etiquetar una mayor gama de prácticas fílmicas, incluidas las ya nombradas, y porque, a su entender, la denominación puede ser útil para remitir a la primera persona del singular y/o a la primera persona del plural, ya que desde su punto de vista el 'yo' es inherente al 'nosotros', si no es al revés (Arfuch, 2012, p. 2).

Piedras, por su parte, se expresa en términos prácticamente idénticos a Lebow en la introducción de El cine documental en primera persona (2014) donde escribe que la denominación 'documental en primera persona', "permite distinguir un grupo amplio de obras que incorporan alguna modulación del yo del cineasta [. . .] como responsable y autor del discurso audiovisual” y que él considera "esta categoría más operativa y precisa que otras”. Solo unas pocas líneas antes, el académico indica que la profusión de documentales en primera persona no es casual; que está en sintonía directa con el giro hacia lo subjetivo y que halla explicación en las transformaciones 
políticas, sociales, culturales y tecnológicas ocurridas en las tres últimas décadas del siglo XX (Piedras, 2014, p. 21-22). La subjetividad de El cielo gira, por tanto, tiene relación directa con el incremento de narrativas del yo ocurrido desde los 80 . No obstante, a mi juicio, el film va más allá de ser un documental subjetivo, autobiográfico, autoficcional o en primera persona. Por los rasgos conceptuales descritos en el apartado previo y por los atributos formales analizados en los próximos párrafos, El cielo gira, como ya apuntaba en la introducción del presente artículo, podría definirse como 'documental contramonumental', como el contramonumento cinematográfico que Álvarez erige a la idea de progreso.

Formalmente, los contramonumentos artístico-arquitectónicos rechazan la apariencia y los materiales característicos de los monumentos tradicionales (Young, 2000, p. 7). Este precepto explica por qué El cielo gira, como documental contramonumental, elude las reglas formales del documental clásico, el que Nichols denomina expositivo y que es asociable a la idea de documental monumental porque tiende a monumentalizar la realidadobjetividad-verdad del discurso que articula. Una estructura paradigmática para configurar el contenido del documental de tipo expositivo incluye el planteamiento de un problema, "la presentación de los antecedentes", un examen de "la complejidad actual" de la cuestión y finalmente "una sección de clausura" que introduce "una solución o una vía hacia una solución” del problema expuesto (Nichols, 1997, p. 48). El film de Álvarez, por el contrario, toma otra apariencia. Conforme con Imma Merino, el uso de la primera persona por parte de la realizadora para narrar, estación a estación, la experiencia de vuelta a su pueblo de origen podría hacer pensar que El cielo gira tiene todo el aspecto de ser un diario personal. Sin embargo, la misma Merino descarta la opción de catalogarlo así porque "el tiempo verbal de la voz de la cineasta remite [no al presente sino] al pasado" (Merino, 2007, p. 24). Justamente es este uso del pretérito al que se refiere Merino una de las razones por las que sostengo que el largometraje, siendo un documental, tiene una apariencia poco común: se asemeja a un cuento.

En contraposición con la hipótesis anterior, Merino afirma que el film no es “propiamente un cuento" (p. 23). No obstante, al mismo tiempo apunta que 
El cielo gira comienza exactamente como si de uno se tratara al señalar que Álvarez empieza su película con la locución "una vez” (oo:00:37); una expresión que precedida por la palabra "érase" daría lugar a la conocida fórmula con la que en la tradición popular se introducen los cuentos. Además, en cuanto a la estructura de la película, Merino sugiere que esta es circular, al indicar la posible relación de significado entre los dos niños, curiosos y expectantes, que figuran en el cuadro que centra las primeras imágenes del largometraje y los dos ancianos, experimentados y reflexivos, que protagonizan las últimas (p. 23). Merino parece claro que distingue en $E l$ cielo gira el semblante de un cuento y aun así, al igual que los partidarios del canon documental objetivista, se resiste a aceptar la idea y la posibilidad de que una forma narrativa ${ }^{16}$ asociada a la fantasía y a la imaginación pueda vincularse al documentalismo, aun cuando esta pueda generar conocimiento sobre la realidad.

Tenga o no tenga el film de Álvarez forma de cuento, sí se puede deducir que El cielo gira es un documental contramonumental no solo por tener una apariencia poco tradicional sino también por el uso no convencional que la directora hace de algunos de los materiales o recursos de los que pueden servirse los documentalistas para hablar del mundo histórico. En las líneas siguientes examino solo dos de estos recursos: la voz en off y el tratamiento no ortodoxo del testimonio de los vecinos como testigos-protagonistas de los hechos ocurridos en Aldealseñor. Respecto al primer recurso, la voz en off, el análisis es de interés no tanto por el empleo del mismo, que de hecho es característico de los documentales expositivos (Nichols, 1997, p. 68), sino por el uso subjetivo que Álvarez hace de él. Si en el documental clásico, la voz en off utiliza la tercera persona para generar impresión de objetividad, la realizadora, convertida en este caso en narradora homodiegética ${ }^{17}$ de la realidad que cuenta, usa la primera persona para construir el documental desde una subjetividad manifiesta. Ella descarta una determinada forma canonizada de reconstruir la realidad, aquella que recurre al ideal de

16 Carl Plantinga afirma que la narración es una modalidad textual que puede estar al servicio del entretenimiento y también de la información y del conocimiento (1997, p. 104). ${ }_{17}$ En la narración homodiegética, narrador y personaje son un mismo sujeto, escindido en dos roles: el yo narrador y el yo narrado (García Landa, 1998, p. 315). 
objetividad como patrón y como esencia del documental cinematográfico puro, porque quiere hacer constar que el del film es su punto de vista sobre la aldea y el progreso vivido y que se vive en ella.

Aunque pueda parecer contradictorio, si no se asume el paradigma objetivista como representativo del canon documental, no tiene por qué existir incompatibilidad entre tener vocación de documentalista y querer presentar, en palabras de Eric Barnouw, la propia versión del mundo (Barnouw, 1993, p. 313). Así lo acreditan las declaraciones de la directora dentro y fuera del film. Dentro del documental, en el primer minuto, Álvarez confiesa que es su profesión la razón que le lleva de vuelta a la aldea: "Yo [hacía años que] planeaba visitar mi pueblo de origen, [para] retratar a sus habitantes y arrancarles cuatro palabras" (00:00:55-00:01:03). Fuera del documental, en una entrevista, al hablar de la presencia de su 'yo' en El cielo gira, la cineasta explica que le parece importante no ocultar "el lugar desde el cual se cuentan las cosas”. Principalmente, porque no encubrir que la persona encargada de la dirección está detrás de un punto de vista supone establecer un nuevo tipo de pacto comunicativo y relacional tanto con los participantes del documental como con los espectadores, basado en un doble compromiso personal y ético con ellos (Merino, 2007, p. 38).

En concreto, en cuanto al uso y al tratamiento de los testimonios de los participantes del documental -el segundo recurso que analizo para poder explicar la forma contramonumental de El cielo gira-, este se puede calificar también de poco ortodoxo al menos por dos motivos. Por un lado, la audiencia solo va a conocer su identidad en caso de que entre ellos se dirijan por el nombre de pila, ya que la directora no recurre en ningún momento al sistema propio de los documentales tradicionales que consiste en identificar a los testigos, como mínimo, por medio de la sobreimpresión en pantalla de nombre y de apellidos. Por otro lado, a diferencia de los documentales convencionales, Álvarez tampoco entrevista a los participantes en el film. No les formula preguntas. Simplemente, encuadra algunas situaciones que viven, las graba y las edita. Conforme con la misma directora, "la convivencia con los vecinos del pueblo [es la que] marcó las estrategias y los dispositivos de guion y rodaje. No se trataba de una puesta en escena, al modo de 
Flaherty, ni de captar la vida de improviso, según la práctica de Vertov [. . .]. Se trataba, más bien, de una puesta en situación” (Álvarez, 2009, p. 77).

De este modo, Álvarez consigue que los espectadores le acompañen en la observación y en la escucha de las conversaciones y de los silencios de los lugareños en distintas localizaciones: en un pequeño huerto junto al cementerio, en los campos colindantes a Aldealseñor, también en el interior de la torre-palacio, en la iglesia y, sobre todo, en la plaza, el principal escenario de las secuencias dialogadas. Los aldeanos hablan libremente de temas como la vida y la muerte, de las noticias del presente, del hoy y del ayer, y del futuro en el que habrá viajes a Marte. En ningún momento, la voz y la cámara de Álvarez se entrometen a pesar de no ser ni querer ser invisibles. La manera excepcional que tiene la cineasta, primero, de trabajar - sin exigencias metodológicas, sin guiones ni de ritmos de rodaje-; y segundo, de construir el film - sin imposiciones conceptuales ni formaleses la que, en contraste con las ideas tradicionales de la teoría documental, establece la credibilidad del trabajo. El cielo gira es ejemplo de aquello que Stella Bruzzi denomina nuevos documentales, prácticas que fundamentan su autenticidad en no pretender ser films objetivos sino en mostrarse abiertamente como productos resultantes de la interacción entre sujetos, cineastas, aparatos cinematográficos y espectadores (Bruzzi, 2006, pp. 910).

Parafraseando a Antonio Weinrichter, el largometraje de Álvarez también puede describirse como prueba, y resultado a la vez, de dos intereses del nuevo cine documental. Por una parte, presentarse "como algo construido", que "difumina la vieja frontera sagrada que lo separaba del cine de ficción” al subrayar "elementos expresivos y dramáticos como la organización narrativa de la exposición". Por la otra, explorar el conocimiento "del sujeto performativo, a uno u otro lado de la cámara" (Weinrichter, 2004, p. 61). A este nuevo tipo de cine documental, descrito por Bruzzi y Weinrichter, no le asusta, según la directora de El cielo gira, poner en juego la subjetividad; tampoco trata de esconder el punto de vista del autor; se sirve, si es preciso, del diálogo con lo ficticio, lo hipotético o lo imaginativo; y emplea a veces el comentario, pero sin prisas por establecer tesis o llegar a conclusiones. La 
misma realizadora, sin referirse en concreto a su largometraje de 2004, razona el porqué de la forma contramonumental del film al confesar qué tipo de cine documental le interesa; aquel que históricamente ha ido unido a la ruptura con los sistemas de creación o producción dominantes (Álvarez, 2009, p. 75).

\section{El poder de la mirada y el derecho a la libre lectura}

En el artículo ¿Por qué el documental? (Álvarez, 2009), aparecido en la revista Arkadin, la directora de El cielo gira alerta sobre el hecho de que, lejos de Aldealseñor, "vivimos en un mundo de producción acelerada de imágenes”. Son imágenes de todo tipo, sigue Álvarez. Algunas informativas y otras publicitarias. A veces, también las hay incluso sermoneantes - dicepor poner sólo unos pocos ejemplos. Todas, afirma la cineasta, "parecen tener prisa por decir algo" y casi ninguna busca dejar “al espectador en paz". Entre unas y otras, asegura la realizadora, "han acabado usurpándole la mirada" a la audiencia. Y lo más paradójico, concluye, es que "a menudo el espectador actual parece haber olvidado que puede reclamar ese poder”. La mirada, sostiene la documentalista, "es el primer derecho [del público], el más genuino" (p. 74). De hecho, uno de los valores contramonumentales de El cielo gira es, en mi opinión, que el film retorna al espectador su poder de mirar, ya que restituye el derecho que tiene de leer las imágenes con libertad. $\mathrm{Al}$ funcionar, comunicativamente hablando, como un contramonumento, el documental encara a la audiencia no como un grupo de destinatarios pasivos sino como individuos, potenciales co-constructores de la memoria del progreso en Aldealseñor.

Entre 2002 y 2003, Álvarez filma, ordena y monta imágenes de la aldea y de la vida de sus habitantes de manera meticulosa para producir un texto cinematográfico que presenta el relato de una experiencia de retorno a Aldealseñor incitada por una búsqueda personal de conocimiento sobre el presente y el pasado del lugar, llevada a cabo desde la subjetividad, y que no tiene como objetivo establecer conclusiones sobre la realidad. De este modo, la cineasta hace viable que el documental pueda ser abordado de múltiples 
maneras. Así puede suceder que, a diferencia de lo escrito en la sinopsis del DVD comercial y de lo publicado por Cobo Durán y Fernández Pichel, la audiencia, si se limita a las imágenes contenidas en el film, pueda interpretar que Álvarez le invita no a asumir el supuesto destino fatídico de la aldea, sino a reflexionar sobre el presente, el pasado y el futuro de los aldeanos en manos del progreso. La realizadora no sugiere a nadie qué tiene qué pensar ni cómo debe actuar ante a la realidad proyectada. En comparación con los documentales clásicos y con los monumentos tradicionales, El cielo gira es una construcción que no acepta difundir y perpetuar un mensaje con estatus de verdad absoluta. Como contramonumento, su objetivo "no es consolar, sino provocar"; "no ser ignorado por sus transeúntes, sino demandar interacción"; "no aceptar gentilmente la carga de la memoria, sino devolverla a los pies de la ciudad[anía]” (Young, 2000, p. 7).

El público, al ver el film, es libre de dar un sentido u otro a la narración; y también de no dárselo. En mi caso, como argumento en los dos apartados anteriores, como espectadora interpreto que El cielo gira es un documental que hace visible la necesidad de debatir sobre la idea de progreso al observar lo que sucede en Aldealseñor, una parte de España, país que a su vez es una parte de Europa. Frente al discurso oficializado y estereotipado de progreso que defiende el acierto de implementar proyectos de inversión económica para modernizar aldeas y pueblos y para, así, poder prevenir y frenar su desaparición, pienso que el documental de Álvarez permite una lectura distinta de la realidad y del recuerdo oficial que quiere construirse de ella. A mi parecer, el largometraje, gracias a su concepción y a su forma, puede leerse como una invitación a un debate no políticamente partidista para revisar la idea de progreso y sobre cómo esta idea se aplica en el terreno de lo real. El cielo gira permite preguntarse qué significa exactamente progresar, más allá de avanzar en el tiempo; quién decide sobre el progreso; cómo este se mide y se evalúa; a quién beneficia en la teoría y en la práctica; y si es sostenible el progreso sin contar con las personas.

Recuperando el ideal de progreso europeo definido por Rifkin —basado en la primacía del desarrollo de una sociedad democrática, diversa culturalmente, partidaria de la calidad de vida y no del crecimiento material ilimitado- 
parece como mínimo debatible e incluso denunciable el hecho de emprender procesos de modernización material y cultural, como los iniciados en Aldealseñor, sin informar ni consultar a la población sobre ellos. Con el objeto de abrir dicho debate, Álvarez podría haber optado por concebir y dar forma a un documental expositivo que, utilizando algunas de las mismas declaraciones de los vecinos que participan en El cielo gira, denunciara tanto la falta de capacidad de decisión de los aldeanos como la opacidad y la incontestabilidad con qué funciona el capital en la aldea. Podría haber utilizado el retrato del presente de los lugareños para concluir por medio de argumentos que la exaltación y el culto a un progreso restringido a lo económico, como el que aparenta vivir Aldealseñor, citando a Alberto Barbeito y Rubén Mario Lo Vuolo, genera en la práctica un progreso socialmente excluyente (1992, p. 19). No obstante, la realizadora se decanta por producir otro tipo de documental, uno contramonumental, porque, además de expresar su punto de vista sobre el progreso de la aldea, rehuye limitarse a reafirmar o enfrentar los discursos preexistentes monumentalizados, tanto los oficiales como los alternativos.

Precisamente, la partícula 'contra'18 que conforma la palabra ‘contramonumento', con base en la definición extraída del Diccionario de la Real Academia de la lengua española (2019), denota oposición o contraposición al 'monumento', a una obra artístico-arquitectónica que, de acuerdo con Riegl, se erige para la difusión en el presente de un determinado discurso sobre el pasado, que se considera digno de mantenerse vivo en la conciencia de las generaciones venideras (Riegl, 1987, p. 23). El prefijo 'contra' en el término 'contramonumento', por consiguiente, refiere a una obra que se opone no a uno u otro discurso, sino a la monumentalización de discursos como si de verdades indiscutibles se tratara. Es sabido que en cualquier debate, partir de posiciones enfrentadas evita el acercamiento de posturas entre las partes y los contramonumentos, como El cielo gira, se erigen, en mi opinión, para todo lo contrario: para abrir la puerta a poder 18 Contra-: "Elemento compositivo prefijo que denota oposición o contraposición"
(Diccionario de panhispánico de dudas, 2005). Recuperado de http://lema.rae.es/dpd/srv/search?key=contra-. 
encontrar intereses comunes en temas de interés general ${ }^{19}$. Los contramonumentos viabilizan de esta manera un cambio de dinámica comunicacional en el espacio público que migraría del enfrentamiento entre poseedores de verdades a la cooperación entre partidarios de la búsqueda colaborativa de conocimiento.

Como la misma Álvarez explica en el artículo de la revista Arkadin citado al inicio de este apartado, como documentalista ella se siente parte de una tradición en el cine en la que el autor ofrece su mirada sobre el mundo histórico a la vez que deja vestigios de su impotencia por abarcarlo en su totalidad y trata de recomponer la realidad con la ayuda de la mirada del espectador (p. 77). Sobre el público de los documentales, la directora, en sintonía con Bruzzi (2006, p. 8), no cree que los espectadores sean simples receptores de conocimiento sobre el mundo histórico, sino que, atendiendo a sus palabras, considera que el conocimiento emerge a través del encuentro entre cineastas, sujetos y la misma audiencia. La cineasta, al abordar un tema complejo y controvertido como el progreso, expresa inequívocamente, dentro del film y en sus declaraciones en los medios de comunicación, la voluntad de relacionarse de un modo no jerárquico con aquellos a los que tradicionalmente se les ha otorgado poco o ningún poder en la estructuración y en la producción del mensaje que difunden los documentales: sus participantes y sus espectadores. Evidentemente, pueden existir muchas otras posibles interpretaciones sobre las intenciones de Álvarez y sobre el funcionamiento de El cielo gira, pero es difícil que alguna concluya que la directora habla de la realidad con la verdad en la mano y desde un púlpito.

En mi opinión, la cineasta hace de El cielo gira un contramonumento porque huye de dos tendencias propias de los discursos propagados por los clásicos documentales expositivos y por los reportajes informativos de los medios de comunicación de masas. La primera, ya apuntada en páginas previas, emitir mensajes que monumentalizan verdades sobre la realidad. La segunda, favorecer, queriendo o $\sin$ querer, el tránsito entre la audiencia de

19 Interés general: "Concepto que resume las funciones que se encomiendan constitucionalmente a los poderes públicos y que concierne a valores y objetivos que trascienden los intereses concretos de ciudadanos o grupos" (Diccionario del español jurídico, 2020). Recuperado de https://dej.rae.es/lema/inter\%C3\%A9s-general. 
emociones ${ }^{20}$ que van desde la preocupación hasta la apatía, al promover la infoxicación y el infoespectáculo en relación a los temas de los que hablan. La 'infoxicación' es un término que refiere al estado de saturación que provoca en el receptor el exceso de información que recibe (Toffler, 1970, pp. 311-15; la traducción es mía). El infoespectáculo, por su parte, es un concepto que pone nombre a la fusión de dos géneros televisivos, información y entretenimiento, con el único fin de captar y mantener la atención de la audiencia (Krüger, 1988, pp. 337-64; la traducción es mía). La directora no es partidaria de fomentar ni la infoxicación ni el infoespectáculo en su trabajo no solo por motivos éticos o estilísticos, también por motivos prácticos. Ya en el primer visionado del largometraje, se puede interpretar que para ella el presente, el pasado y el futuro del progreso en Aldealseñor, en España y en Europa no es necesariamente interés de una o de unos, de una u otra forma, nos concierne a todos ${ }^{21}$, con independencia de orígenes y de preferencias políticas.

En línea con Severo Catalina ${ }^{22}$ - autor del libro La verdad del progreso, con quien Álvarez es posible que compartiera pocas afinidades empezando por el dudoso acierto del título del volumen referido-, El cielo gira busca que los espectadores eviten partidismos y no reduzcan "la idea de progreso a los estrechos límites las contiendas actuales, enlazándola con el doloroso tema de los intereses políticos o en las formas de gobierno" (Catalina, 1862, p. IV). Las dos secuencias de la aparición por el pueblo de los coches propagandísticos de los dos principales partidos políticos en España, con sus carteles y sus himnos ruidosos a la caza de votos durante la Campaña electoral, secundan esta lectura. En la primera secuencia, el público puede

20 Sarah Ahmed estudia la función que tienen las emociones en la construcción de una colectividad. Si bien parecería que las emociones son privadas, pues generalmente se les toma como una manifestación de la psique de cada persona, Ahmed sugiere que también son públicas, ya que se construyen, circulan y se significan a través de un imaginario colectivo (Ahmed, 2004, pp. 117-39).

${ }^{21}$ Leonor Arfuch afirma que "todo relato de la experiencia es, en un punto, colectivo/a, expresión de una época, de un grupo, de una generación, de una clase, de una narrativa común de identidad" (Arfuch, 2007: 79).

${ }_{22}$ Severo Catalina fue político conservador y ministro de Fomento hasta La Gloriosa, revolución de 1868 que supuso el fin del reinado de Isabel II y el inicio del período denominado Sexenio Democrático (1868-1874). El alzamiento fue una "brusca sacudida en la historia del siglo XIX español" (López-Cordón, 1976, p. 1), ya que constituye el primer intento en la historia de España de establecer un régimen político democrático. Para unos, significó un progreso político. Para otros, indudablemente, no. 
observar que los representantes del partido socialista afirmando que quieren gobernar para "todos y todas" no llevan a los aldeanos, todos ellos de edad avanzada, más que "caramelos, globos y condones" (01:11:22-01:12:46). En la segunda secuencia, los espectadores son testigos de cómo la paz y el sosiego de los que pueden disfrutar las personas, los animales y los parajes de la zona a la hora de la siesta se ven interrumpidos por el auto de campaña del partido popular que inmediatamente después de colgar el cartel solicitando el voto para su organización política, se aleja del lugar (01:31:13-01:34:15).

El cielo gira, como documental sobre un tema polémico como es la aplicación de la idea de progreso a la realidad, no expresa una sola crítica hacia la actuación de los dos partidos políticos. No da eco a las posibles propuestas de unos u otros para encontrar soluciones para preservar una forma de vivir en Aldealseñor y en poblaciones equiparables. No difunde el discurso oficializado por casi todos ellos en favor de poner en marcha proyectos de inversión económica para modernizar pueblos y para evitar así su despoblación y su muerte. El film no empodera los códigos mediante los cuales el discurso dominante naturaliza una determinada interpretación y comprensión de la realidad. Tampoco lo subvierte, no se constituye en contra de él. No es, como se ha advertido, que el largometraje de Álvarez sea aideológico. Como discurso sobre la realidad es una construcción y toda construcción discursiva es una forma de ideología (Pêcheux, 1982, pp. 18586). La ideología contramonumental de El cielo gira se ha puesto de manifiesto a lo largo del presente artículo y queda evidenciada también a través de la definición que su realizadora da del documental al describir los rasgos conceptuales, formales y funcionales que lo singularizan: una "crónica [subjetiva] de unos hechos, que respeta el tiempo de la vida y la verdad de la acción” (Álvarez, 2009, p. 77).

\section{Referencias bibliográficas}

Ahmed, S. (2004). Affective Economies. Social Text, 2, pp. 117-39.

Álvarez, M. (2009). ¿Por qué el documental? Arkadin, 2, pp. 74-77.

Arfuch, L. (2007). El espacio biográfico. Dilemas de la subjetividad contemporánea. Buenos Aires: Fondo de Cultura Económica. 
Arfuch, L. (2018). La vida narrada: memoria, subjetividad y política. Chile: Editorial EDUVIM.

Barbeito, A. y Lo Vuolo, R. M. (1992). La modernización excluyente: transformación económica y estado de bienestar en Argentina. Argentina: Losada.

Barnouw, E. (1993). Documentary: A History of the Non-Fiction Film. Nueva York: Oxford University Press.

Bruzzi, S. (2006). New Documentary: A Critical Introduction. Londres: Routledge.

Cobo Durán, S. y Fernández Pichel, S. N. (2016). La 'imagen resistencia' en la obra documental de Mercedes Álvarez. En V., Guarinos (Ed.), Apuntes de cine: Homenaje a Rafael Utrera, pp. 27-37. Madrid: Delta.

Consejería de Cultura y Turismo de la Comunidad de Castilla y León (19-82013). Información relativa al expediente de declaración en la categoría de Monumento, del Bien de Interés Cultural denominado «Torre y Palacio Medieval» en Aldealseñor (Soria), delimitando su entorno de protección. BOCL, 158, pp. 56188-90. Recuperado de http://bocyl.jcyl.es/boletines/2013/o8/19/pdf/BOCYL-D-1908201365.pdf.

Cuevas, E. Cycles of Life: El cielo gira and Spanish Autobiographical Documentary. En A., Lebow (Ed.), The Cinema of Me: The Self and Subjectivity in First Person Documentary, pp. 79-97. Londres: Wallflower Press.

De La Torre Espinosa, M. (2015). Cines del yo: el documental autoficcional contemporáneo español. Bulletin of Hispanic Studies, 92, pp. 567-82. https://doi.org/10.3828/bhs.2015.33

Estrada, I. M. (2013). Otro viaje inquisidor hacia el pasado: El cielo gira (2005), de Mercedes Álvarez. En I.M., Estrada (Ed.), El documental cinematográfico y televisivo contemporáneo: memoria, sujeto y formación de la identidad democrática española, pp. 115-34. Woodbridge: Tamesis.

García Landa, J. A. (1998). Acción, relato, discurso: estructura de la ficción narrativa. Salamanca: Ediciones Universidad de Salamanca.

Krüger, Udo Michael (1988), Infos-Infotainment-Entertainment? Revista Media Perspektiven, 10, pp. 637-64.

Lebow, A. S. (2012). The Cinema of Me: The Self and Subjectivity in First Person Documentary. Londres: Wallflower Press.

López-Cordón, M. V. (1976). La revolución de 1868 y la I República. Madrid: Siglo XXI.

Lyotard, J.-F. (1994). La posmodernidad (explicada a los niños). Barcelona: Gedisa.

L-Quiñones, A. (2007). Más allá de la nostalgia: espacio, modernización y democracia en El cielo gira y En construcción. Revista de Estudios Hispánicos, 2, pp. 363-86. 
Merino, I. (2007). Mercedes Álvarez. En J., Cerdán y C., Torreiro (Eds.), Al otro lado de la ficción. Trece documentalistas españoles contemporáneos, pp. 12-43. Madrid: Cátedra.

Ministerio de Cultura y Deporte. (2004). Catálogo de cine español. Recuperado de https://sede.mcu.gob.es/CatalogoICAA/Peliculas/Detalle?Pelicula $=450$ 02.

Nichols, B. (1997). La representación de la realidad. Cuestiones y conceptos sobre el documental. Barcelona: Paidós.

Nisbet, R. (1979). The Idea Of Progress. Literature of Liberty (vol. II), 1, pp. 33-35. http://oll-resources.s3.amazonaws.com/titles/1290/035305_1979v1_Bk_Sm.pdf

Pêcheux, M. (1982). Language, Semantics and Ideology. Londres: Macmillan.

Piedras, P. (2014). El cine documental en primera persona. Buenos Aires: Paidós.

Plantinga, C. (1997). Rethoric and Representation in Nonfiction Film. Londres: Cambridge U.P.

Rancière, J. (2001). La fábula cinematográfica: reflexiones sobre la ficción en el cine. Barcelona: Paidós.

Renov, M. (2004). The Subject of Documentary. Minnesota: University of Minnesota Press.

Riegl, A. (1987). El culto moderno a los monumentos. Caracteres y origen. Madrid: Editorial Visor Distribuciones.

Rifkin, J. (2004). The European Dream: How Europe's Vision for the Future is Quietly Eclipsing the American Dream. Nueva York: Penguin.

Terdiman, R. (2018). Discourse/counter-discourse: The Theory and Practice of Symbolic Resistance in Nineteenth-Century France. Nueva York: Cornell U.P.

Toffler, A. (1996). Future Shock. Nueva York: Bantam Books.

Varda, A. (2014). Agnès Varda: Interviews. Ed. Thomas Jefferson Kline. Jackson: University Press of Mississippi.

Weinrichter, A. (2004). Desvíos de lo real: el cine de no ficción. Madrid: T\&B Editores.

Young, J. E. (2000). At Memory's Edge: After-images of the Holocaust in Contemporary Art and Architecture. New Haven: Yale U.P. 